\title{
A IDENTIDADE LÉSBICA COMO EXPERIÊNCIA CREDÍVEL DE EXISTÊNCIA DENTRO DO COLETIVO LGBT LUTAS E CORES DE CARUARU/PE
}

\author{
LESBIAN IDENTITY AS A CREDIBLE EXPERIENCE OF EXISTENCE WITHIN THE LGBT COL- \\ LECTIVE STRUGGLES AND COLORS OF CARUARU I PE
}

Filipe Antônio Ferreira da Silva', Allene Carvalho Lage ${ }^{2}$

RECEBIDO: 09/01/2019 | ACEITO: 26/05/2019

DOI: $10.5902 / 2317175836321$

\section{RESUMO}

Nossa problematização pretende investigar quais as experiências das mulheres lésbicas do Coletivo LGBT Lutas e Cores no enfrentamento da lesbofobia e do sexismo. Para realizarmos essa coleta, elencamos como objetivo geral conhecer quais são as experiências das mulheres lésbicas do Coletivo LGBT Lutas e Cores no enfrentamento da lesbofobia e do sexismo, e como objetivos específicos procuramos sistematizar as experiências das mulheres lésbicas do Coletivo LGBT Lutas e Cores no enfrentamento da lesbofobia e sistematizar as experiências das mulheres lésbicas do Coletivo LGBT Lutas e Cores no enfrentamento do sexismo. Embasaram teoricamente essa investigação pesquisadores das temáticas de Gênero, Sexualidade e Diversidade Sexual, juntamente com as perspectivas pós-estruturalistas. Adotamos a metodologia qualitativa para guiar nossos achados na pesquisa. As análises apontam que é no enfrentamento da lesbofobia e do sexismo que as militantes lésbicas do Coletivo LGBT Lutas e Cores encontram suas forças e seus espaços de voz e vez para atuar como protagonistas. As estratégias de enfrentamento e a busca da promoção e da valorização das identidades lésbicas são fabricadas como respostas práticas ao preconceito naturalizado e aceito livremente pela sociedade.

Palavras-chave: Identidade; Lesbianeidade; Sexismo; Lesbofobia

\footnotetext{
1 Mestrando do Programa de Pós-Graduacão em Educacão Contemporânea pela Universidade Federal de Pernambuco - Centro Acadêmico do Agreste (UFPE/PPGEDUC/CAA). Pós-graduando em Filosofia e Sociologia - Universidade Cândido Mendes - UCAM (2017). Licenciado em Pedagogia pela Universidade Federal de Pernambuco/ Centro Acadêmico do Agreste - UFPE/CAA (2016). Atua como Professor da Universidade Paulista (UNIP - Pólo Caruaru) e atua como Pedagogo no CREAS municipal na Prefeitura de Caruaru/PE.

2 Pós-doutora em Direitos Humanos pelo PPGDH/UFPE (2016). Pós-doutora em Educação na UFRGS (2012). Doutora em Sociologia pela Universidade de Coimbra (2006). Mestre em Administração Pública pela Fundação Getulio Vargas - RJ (2001). Graduada em Administração - Faculdades Integradas Anglo Americano - RJ (19933).

Professora Associada da Universidade Federal de Pernambuco
} 


\section{ABSTRACT}

Our problematization intends to investigate the experiences of the lesbian women of the LGBT Collective Fights and Colors in the face of lesbophobia and sexism? To accomplish this collection, we have as a general objective to know the experiences of lesbian women of the LGBT Collective Fights and Colors in the face of lesbophobia and sexism and as specific objectives we seek to systematize the lesbian women's experiences of the LGBT Collective Fights and Colors in coping with lesbophobia and to systematize the lesbian experiences of the LGBT Collective Fights and Colors in the face of sexism. These researchers were theoretically based on the themes of Gender, Sexuality and Sexual Diversity, together with the poststructuralist perspectives. Our analyzes point out that it is in the face of lesbophobia and sexism that the lesbian activists of the LGBT Collective Fights and Colors find their strengths and their spaces of voice and instead to act as protagonists. The coping strategies and the search for the promotion and valorization of lesbian identities are fabricated as practical answers to naturalized prejudice and freely accepted by society.

Keywords: Identity; Lesbianeidade; Sexism; Lesbophobia

\section{Introdução}

Vivenciamos uma nova era de sociedade, conceituada teoricamente como pós-modernidade (SANTOS, 2006), onde os arranjos globais e locais fabricam os papéis os quais nós, enquanto sujeitos sociais, devemos cumprir. É dentro desses arranjos sociais que as questões de cultura, diferença e educação são interpeladas por um único modelo hegemônico de sociedade, a regra heteronormativa (BORRILLO, 2010; PRADO \& MACHADO, 2008; LOURO, 1997). Consolidada como norma a ser seguida e padronizada, a regra heteronormativa faz com que os sujeitos sociais que fogem dessa norma são sejam vistos e acionados como subversivos e marginais, pois quebram com a cultura dominante, desestabilizam a diferença e transformam a educação em uma bandeira de luta contra as opressões, discriminações e subalternizações.

Mas quem são essas pessoas que quebram com a classificação social e a monocultura do saber imposto pela cultura dominante e do cânone científico? Pergunta essa que fazemos dentro de um plano micro e macro, demarcado por relações de poder e de forte resistência. Historicamente, as mulheres, os negros e negras, os indígenas, os camponeses e camponesas, os pobres, os deficientes, os estudantes e os LGBTs (lésbicas, gays, bissexuais, travestis e transexuais) fazem um "verdadeiro carnaval" como canta Caetano Veloso. São identidades marginais, subalternizadas, marcadas pelo silenciamento, desenhados como não-existentes (SANTOS, 2003). Diante desses grupos transgressivos, este artigo se propõe a investigar mais sistematicamente a identidade lésbica como experiência credível de existência, e seu enfrentamento em relação a lesbofobia e ao sexismo.

O debate da lesbofobia no campo da educação se traduz como uma verdadeira guerra contra-hegemônica ao modelo heterossexual que estamos respirando cotidianamente. É na escola que os corpos são padronizados, en- 
quadrados e submetidos a uma vigilância quase que sagrada. Papéis sexuais são produzidos, sexo e gênero hierarquizados em relação de poder e de subalternização. Nada pode fugir do cânone normativo imposto pela sociedade. Como os corpos transgressivos das meninas lésbicas fogem e desestabilizam as normas de gênero e sexualidade nos seus locais de militância/ativismo? Como é feita essa subversão? A diferença e a identidade são negociadas? Os espaços disciplinadores, como a escola e a família, conseguem lidar com esses dilemas ou simplesmente seguem a lógica da escala dominante? (SANTOS, 2003).

A fim de problematizar essas questões, este artigo se propõe a investigar quais são as experiências das mulheres lésbicas do Coletivo LGBT Lutas e Cores no enfrentamento da lesbofobia e do sexismo. Esse questionamento surge a partir de discussões teóricas e práticas que surgiram na Disciplina Eletiva "Fundamentos para uma Educação não-sexista" do Programa de Mestrado em Educação Contemporânea, ofertada pela professora Doutora Allene Lage (UFPE-PPGEDUC-CAA) na Universidade Federal de Pernambuco - UFPE, localizada no Centro Acadêmico do Agreste (campus universitário construído no programa de interiorização de Universidades Federais implementado na gestão do ex-presidente Lula e da presidenta Dilma Rousseff). A relevância de disciplinas como essa trazem em seu campo teórico e empírico a audaciosa perspectiva de uma educação forjada no centro dos movimentos sociais e dentro de uma perspectiva de educação feminista, visto que vivemos sobre uma despolitização de movimentos sociais e em busca de uma educação de cunho positivista, com abordagens religiosas, silenciando mais uma vez a forma plural e híbrida dos corpos que habitam as escolas.

Para realizarmos essa coleta, elencamos como objetivo geral estudar quais são as experiências das mulheres lésbicas do Coletivo LGBT Lutas e Cores no enfrentamento da lesbofobia e do sexismo, e como objetivos específicos procuramos sistematizar as experiências das mulheres lésbicas do Coletivo LGBT Lutas e Cores no enfrentamento da lesbofobia e sistematizar as experiências das mulheres lésbicas do Coletivo LGBT Lutas e Cores no enfrentamento do sexismo.

\section{Discussão Teórica}

\subsection{La Cadena Simbólica}

O conceito teórico estudado pela professora Doutora Olga Viñuales ${ }^{3}$ sobre "la cadena simbólica" nos traz uma abordagem sobre como podemos pensar a identidade lésbica pelo viés da relação entre o sexo e o gênero, as práticas sexuais e a orientação sexual. Sendo todos esses elementos fundantes nas discussões de gênero e sexualidade, os escritos de Olga Viñuales se fazem emergentes para que possamos problematizar toda essa cadeia simbólica imposta pelo cânone heteronormativo que respiramos cotidianamente.

3 Doutora em Antropologia Social, membro do I.C.A. (Institut Català d'Antropologia), da F.E.S. (Federación española de Sociologia) e investigadora associada do XIRSS (xarxa interdisciplinar de recerca em sexualitat, societat i salut). 
Historicamente, os entraves sobre sexo e gênero são estudados por meio das áreas da saúde, como a biologia, a medicina, a psiquiatria e a psicologia. Essas áreas, ao longo dos séculos, procuram demonstrar como o sexo e o gênero são reproduzidos nas sociedades e qual a melhor maneira de se portar diante da vida pública e da vida privada. Como a referência sempre foi a heterossexual, é cabível que as práticas sexuais entre pessoas do mesmo sexo fossem, ao longo dos anos, tratadas como aversão, perversão e anomalia, algo não credível de existência. A religião cristã e o discurso da reprodução são, até hoje, os motivos pelos quais algumas religiões neopentecostais conservadoras e alguns setores da igreja católica usam como forma de validar as práticas sexuais de pessoas não homossexuais e condenar as práticas afetivas de pessoas não heterossexuais. Viñuales nos fala que:

Desde la Antiguedad hasta el siglo XIX se pensaba que sólo existían um sexo y dos géneros. Esta división de los géneros tenía una ligitimación sobrenatural en la religión. Desde luego el género masculino era el más valorado por su papel de gerador de vida. A la mujer se le reconocía un género próprio y distinto del masculino por su papel passivo. Sin embargo, hombres y mujeres no se distinguían por pertencer a sexos distintos, radicalmente diferenciados. Al contrario, se consideraba que la mujer no era otra cosa que um hombre imperfecto. (VIÑUALES, 2002, p. 38).

É nesse local de passividade que historicamente as mulheres são lidas como seres inferiores, sentimentais, abjetos e residuais e os homens como seres procriadores da vida, eréteis e dominadores. Todo esse discurso fundou as concepções científicas sobre os sexos e os gêneros. O sexo estaria para a reprodução da espécie, numa relação heterossexual, e o gênero acoberto de uma essencialização dos papéis atribuídos aos homens e as mulheres. Dentro desse panorama geral, a heterossexualidade foi fabricada discursivamente como a regra e a norma ser seguida. A sexualidade é ligada a moral, aos bons costumes e a uma vida saudável. O gênero e a identidade de gênero estariam em plenitude com o sexo biológico e o desejo sexual, bem como os comportamentos estariam ligados a reprodução e a uma relação monogâmica, distribuídas em pares dicotômicos (homem/mulher, macho/fêmea). É dentro desse contexto que Olga Viñuales (2002) nos apresenta de forma estrutural a origem da cadeia simbólica que nós vivenciamos desde o nosso nascimento.

Las diferencias entre hombres y mujeres se explicaban em términos de sua diferente naturaleza sexual, es decir, de la posesión de determinados caracteres. Sexo e género quedaban así estrechamente ligados, se prescrebía la cópula heterosexual y se establecía la reproducción como finalidad única de la sexualidad humana, quadando cualquier situación intermedia - como el hermafroditismo (intersexualidade), la transexualidad o la homossexualidad, que en épocas anteriores habían sido consi- 
A IDENTIDADE LÉSBICA COMO EXPERIÊNCIA CREDÍVEL DE EXISTÊNCIA DENTRO DO COLETIVO LGBT LUTAS E CORES DE CARUARU/PE

derados como variantes del ideal - excluida del ámbito de la normalidade, y relegada al de las anomalias y las patologia. Este nuevo discurso dicotómico de la medicina se extendió y se institucionalizó en la sociedad, consolidando una cadena simbólica que vinculaba entre sí sexo, género, orientación sexual y prácticas sexuales. (VIÑUALES, 2002, p. 38-39, grifo nosso).

As identidades sexuais produzidas pelo discurso médico e científico no século XIX nomearam as noções de sexo, sexualidade e gênero, hierarquizando e fabricando, dessa forma, os desejos, os comportamentos e as identidades. Sistematizando toda essa produção médica-científica do fenômeno da homossexualidade produzida no século XIX até o XX, elaboramos essa tabela que destaca os principais pesquisadores, suas obras fundamentais e ano de publicação.

Quadro I - Produções científicas pautadas no desdobramento da homossexualidade

\begin{tabular}{|c|c|c|}
\hline $\begin{array}{l}\text { Grandes Pesquisadores } \\
\text { do fenômeno da } \\
\text { Homossexualidade }\end{array}$ & Principal obra & $\begin{array}{l}\text { Ano de } \\
\text { publicação }\end{array}$ \\
\hline $\begin{array}{l}\text { Karl Heinrich Ulrich (1825- } \\
\text { 1895) }\end{array}$ & $\begin{array}{l}\text { Vindex (The Vindicator): Social and Legal Studies on Man- } \\
\text { Manly Love }\end{array}$ & 1864 \\
\hline $\begin{array}{l}\text { Károli Maria Kertheny (1824 } \\
\text { - 1882) }\end{array}$ & $\begin{array}{l}\text { Parágrafo } 143 \text { do Código Penal Prussiano datado em } 14 \\
\text { de abril de } 1851 \text { e as Suas Reafirmações em Forma do } \\
\text { Parágrafo } 152 \text { no Código Penal Proposto na Nordeutscher } \\
\text { Bund }\end{array}$ & 1869 \\
\hline Krafft - Ebing (1840 - 1902) & Psychopathia Sexualis & 1886 \\
\hline Hnery Havelock Ellis & Studies in the Psychology & 1897 \\
\hline Alfred Kinsey ( & Comportamento Sexual no Homem Humano & 1948 \\
\hline $\begin{array}{l}\text { Simon LeVay (1943- } \\
\text { presente) }\end{array}$ & $\begin{array}{l}\text { A Difference in Hypothalamic Structure between } \\
\text { Heterosexual and Homosexual Men }\end{array}$ & 1991 \\
\hline
\end{tabular}

Fonte: SIMÕES; FACCINI, 2009

Grandes sexólogos europeus escreviam sobre as questões da homossexualidade, desde o século XIX até o século XX, as quais foram responsáveis por uma teoria moderna do debate das sexualidades. Destacamos as contribuições do médico e psicólogo britânico Henry Havelock Ellis (1859-1939) em sua famosa obra "Studies in the Psychology of sex", em que escreveu cientificamente sobre as questões da homossexualidade, chamada na época de "inversão sexual". Recebeu também as contribuições do crítico literário e poeta John Addington Symonds (1840-1893).

Grandes são os debates sobre as questões congênitas da homossexualidade. Mesmo vivenciando um importante marco no Brasil, em 1985, da retirada da homossexualidade como patologia do Conselho Federal de Medicina e do Código Internacional de Doenças (CID) da OMS - Organização Mundial de Saúde no dia 17 de maio de 1990, nos deparamos com grupos conservadores que tentam transformar as identidades LGBTs em cura. Por vezes, nas redes sociais, surgem psicólogos, médicos e igrejas pentecostais defendendo a utopia 
que pode ajudar os LGBTs a se curarem ${ }^{4}$ da homossexualidade. Todas essas teorias violentas surgem como reforço da heteronormatividade, pois somente a heterossexualidade é vivenciada como norma sexual. Como nos falam Simões e Fachine (2009):

\begin{abstract}
Em suposto cultural poderoso é que tem de existir uma conexão fundamental entre sexo do corpo (macho ou fêmea), a identidade de gênero (a convicção de ser "masculino" ou "feminina" conforme os atributos, comportamentos e papeis convencionalmente estabelecidos para os machos e as fêmeas) e a orientação do desejo para o sexo oposto (machos desejam fêmeas e viceversa) (SIMÕES; FACCHINNE, 2009. p. 31)
\end{abstract}

O que define a orientação sexual e a identidade de gênero? Várias abordagens da psicologia, sociologia, biologia e psicanálise, entre outras ciências, se aventuraram a tentar decifrar esse código. Hoje sabemos que as identidades não são fixas nem inatas, mas bastante flexíveis, híbridas e inconstantes. No entanto, o movimento LGBT trata a identidade como inata e fixa para pautar a importância de políticas públicas. Afinal, combater a heteronormatividade é um enfrentamento muito bem articulado pelos ativistas, qualquer fresta encontrada sobre nossa identidade sexual que a faça ser passível de escolha ou opção, a LGTBfobia se faz presente e tenta nos silenciar.

A biologia, assim como outras ciências do caráter da saúde, tentou e tenta até hoje encontrar uma base sólida que explique nossos desejos, nossos comportamentos e nossas identidades. Hoje vivemos uma diversidade de perfis sexuais, homens-trans que desejam homens gays, mulheres lésbicas com comportamento bissexual, gays e lésbicas com identidades fluídas, e heterossexuais que sentem desejos homossexuais, mas que não praticam. Até mesmo a indústria de filmes adultos é um bom exemplo de desejo, comportamento e identidade que não seguem uma lógica binária hétero/homo. Vários homens héteros cis gênero fazem filmes pornôs com homens gays, ocupando o papel de ativo ou passivo, e vivem suas vidas com suas esposas ou namoradas. A diversidade sexual é múltipla, não segue uma linha linear, tão pouco sistematiza qual o desejo certo, o comportamento sexual normal e uma identidade fixa. Há uma quebra com os binarismos, uma ruptura necessária e urgente.

Lesbianeidade: entre identidades e resistências

No dia 28 de junho de 1969, ocorreu no bar Stonewall Innm, em Nova lorque, um grande grito por liberdade. Nesse bar e nessas ruas marginais da Christopher Street, no bairro Greenwich Village, frequentado por homossexuais masculinos e femininos, travestis, bissexuais entre outras identidades sexuais, aconteceu uma grande revolução contra as barbaridades da polícia local

4 Para se ter uma ideia do nível de preconceito institucionalizado existente na sociedade, um juiz federal, em setembro de 2017, aceitou o argumento de um grupo de psicólogos que moveu ação contra a Resolução do Conselho Federal de Psicologia - CFP 01/99 (BRASIL, 1999), que proíbe profissionais de Psicologia utilizarem técnicas terapêuticas de reorientação sexual, determinando que o CFP não atue de modo a proibir que psicólogas/os façam atendimentos que visem a reorientação sexual. Esta determinação mostra-se muito danosa, pois reforça antigos estigmas nos quais reconhecem as homossexualidades dentro de um contexto patologizante. 
que discriminava com violência seus frequentadores. Dessa noite em diante, a data se consolida no mundo inteiro como o dia do Orgulho LGBT (gay power). Nos dias atuais, ainda comemoramos essa data com um forte desejo de mudança e de desestabilização da LGBTfobia que nos cerca e nos viola em direitos, dignidade e liberdade.

A partir desse grande despertar pelo orgulho de ser LGBT, os ativistas também confrontaram de forma política a questão do estigma da homossexualidade na época, criando as categorias gays e lésbicas como forma de vida subversiva e não linear, tão pouco padronizada ao modelo heterossexual consagrado como norma e regra. Essa nova onda por uma identidade marginal foi desempenhada por muitos ativistas homossexuais, porém, espaços de sociabilidade homossexual menos radicais se formaram com mais frequência e fôlego nas cidades de São Francisco, Nova lorque e Sidney. Como bem explícita Simões e Facchinne (2009):

O que veio a prevalecer, porém, foi a perspectiva de tendências menos radicais, que reencamparam a concepção de uma minoria gay e lésbica e, e vez de falarem de ruptura de papéis e identidades, reivindicaram aos gays os direitos de inclusão equivalentes ao de grupos minoritários. São Francisco, epicentro da boemia hedonista beatnik e da contracultura hippe nos anos 1950 e 1960, foi a cidade em que esses desenvolvimentos se deram com intensidade exemplar, com a formação de territórios urbanos ocupados de modo regular e predominante por gays e lésbicas, e a conversão desses grupos em uma força econômica e política importante (SIMÕES E FACCHINNE, 2009. p. 46).

Em meados da década de 1970, o gay power deu continuidade com toda sua força nos EUA, mas também outras demandas surgiram dentro do movimento LGBT, deixando de lado as performances subversivas de gênero, como as de travestis, transexuais, gays afeminados e Drags Queens. Uma nova onda emergente homossexual buscou a valorização do corpo sarado, jovem, erétil, viril e ativo: uma imagem de um homem gay que despertasse desejos, não só no universo homossexual, como também heterossexual. Em meio a essas novas configurações, as bixas afeminadas, os gays velhos e as lésbicas foram procurando outros meios de lutar contra a descriminalização de suas identidades, pois a valorização do gay branco, jovem, sarado e viril estava em alta naquele momento.

As lésbicas nesse período criaram grandes espaços de sociabilidade, buscavam mais visibilidade, pois eram ofuscadas pela predominância gay nos espaços e coletivos em prol da diversidade sexual. Foram longe nesse confronto e distanciamento, propondo uma radicalização nas questões de gênero, sexualidade, e uma nova sociedade de lésbicas, partilhando e vivenciando suas experiências sem uma aproximação com grupos de gays, nem do emergente coletivo de feministas que eclodia na Europa. 
Nesse embate, surgiram grandes teóricas feministas e lésbicas, que, por meio dos escritos científicos, divulgavam as experiências de suas identidades, denunciando as relações patriarcais, machistas, androcêntricas e lesbofóbicas. Uma das maiores precursoras dessa onda foi a poeta e escritora Adrienne Rich (1929-2012) que escreveu o artigo "Heterossexualidade compulsória e existência lésbica" em 1980. Ao escrevê-lo, Rich denuncia o caráter compulsório da heterossexualidade na vida das mulheres, principalmente das mulheres lésbicas e feministas. Faz uma crítica ao modelo feminista que acredita que a sexualidade lésbica não passa de um desejo alternativo (fetiche), e fundamenta a importância de uma inteligibilidade entre as mulheres, independentemente de suas orientações sexuais e identidade de gênero. Como bem problematiza:

\begin{abstract}
A identificação entre mulheres é uma fonte de energia e de poder feminino potencial, contido e minimizado pela instituição da heterossexualidade. A negação da realidade e da visibilidade da paixão das mulheres por outras mulheres, da escolha das muIheres por outras como suas aliadas, companheiras de vida e de comunidade, ao se obrigar que tais relações sejam dissimuladas e até desintegradas sob intensa pressão tem representado uma perda incalculável do poder de todas as mulheres em mudar as relações sociais entre os sexos e de cada uma de nós se libertar. Hoje em dia, a mentira da heterossexualidade compulsória feminina aflige não apenas a produção acadêmica feminista, mas toda profissão, todo trabalho de referência, todo currículo, toda tentativa de organização, toda relação ou conversação por onde ela se apresenta (RICH, 1980, p. 41).
\end{abstract}

A defesa de um Continuum lésbico proposto por Adrienne Rich (1980) desestabiliza a heterossexualidade compulsória e propõe uma sororidade entre as mulheres, em que as experiências de vida de cada uma são importantes e credíveis de existência, seja na política, nas identidades ou nas relações amorosas. As mulheres lésbicas, assim como os gays, também sofriam com a heterossexualidade compulsória por meio de xingamentos cotidianos, era comum interpelarem as lésbicas com gritos de butch e dyke, que, em nossa língua, seriam respectivamente caminhoneira e sapatão. Assim como o termo homossexual foi ressignificado pelos ativistas LGBTs, as lésbicas também ressignificaram os temos de butch e dyke para pautar uma diversidade política e identitária lésbica, assumindo a não-feminização compulsória de sua existência e buscando mais liberdade e visibilidade na sociedade americana.

Segundo as contribuições de Olga Viñales (2002), as lésbicas quebraram com os papéis de gênero imposto pelo seu gênero - mulher - e desafiaram a lógica da classificação social (SANTOS, 2003), fazendo e refazendo sua identidade como um local de resistência e de autoconhecimento: sendo mulheres que amam outras mulheres: 
Esta manera estereotipada de pensar la lesbiana, como mujer masculina, negadora de los roles de género, subyace todavía en el imaginário popular generando desigualdades y discriminación ante la ley y em las relaciones de parentesco. Además, estas definiciones han desempeñado un papel fundamental en la vida de las mujeres que, sorprendiéndose a sí mismas com determinados sentimientos acerca de las de su próprio género. (VIÑUALES, 2002, p. 73).

É nessa busca por uma identidade livre de estereótipos sexistas e lesbofóbicos que, na contemporaneidade, as mulheres lésbicas buscam espaços de sociabilidade entre seus pares ou na inserção em coletivos e movimentos sociais ${ }^{5}$ de perspectiva feminista e LGBT. Como exemplo desses espaços cosmopolitas de ações antilesbofóbicas e de combate ao sexismo, no interior de Pernambuco, no agreste, a explosão de coletivos e movimentos sociais feministas e LGBTs são exemplos de resistência contra a onda conservadora mobilizada por igrejas evangélicas fundamentalistas, por regimes de governo de cunho neoliberal que não atendem as demandas sociais, e por monoculturas do saber que silenciam e negam os saberes produzidos nos espaços sociais.

Em Caruaru-PE, destacamos alguns coletivos em prol da visibilidade lésbica, como o Coletivo LGBT Lutas e Cores, a UJS (União da Juventude Socialista) Feminista, a Marcha Mundial das Mulheres (núcleo agreste) e o Movimento de Mulheres Olga Benário. Todos esses coletivos trazem em suas intencionalidades pedagógicas ${ }^{6}$ a visibilidade lésbica em suas formações políticas e em análises de conjunturas.

\subsection{Práticas Educativas Não-Sexistas}

As mulheres feministas iniciaram uma verdadeira revolução desde a década de 1960 em diante. Começaram a introduzir os estudos da mulher nas várias ciências, trazendo ao debate características universalizantes femininas, denunciando sua invisibilidade e criando espaços de sociabilidade para reescrever a história e "até pretensões mais ambiciosas de "subversão dos paradigmas teóricos vigentes" (LOURO, 1997, p. 18). As pesquisadoras feministas denunciavam a neutralidade da ciência, assumindo uma subversão ao escrever e ao interpelar os discursos ocidentais sacralizados pela monocultura do saber e do rigor do saber (SANTOS, 2003).

As epistemologias feministas, assim como outros campos do conhecimento contraculturalista, possuem como objetivos, segundo Louro (1997) e Margareth Rago (1998):

5 Como campo teórico e empírico, os movimentos sociais são verdadeiros lugares de cultura contra hegemônica, de valorização das identidades e utopia de mudança social em seus vários aspectos (históricos sociais, antropológicos, psicológicos e educacionais).

6 As concepções feministas na luta avançaram na construção de novos imaginários sociais, onde a presença da mulher tem alcançados novos estatutos de visibilidade social, porém nos livros didáticos ainda estẵo em descompasso no que se refere à representação da mulher e do seu papel social (LAGE, 2013, p. 130). 
Objetividade e neutralidade, distanciamento e isenção, que haviam se constituído, convencionalmente, em condições indispensáveis para o fazer acadêmico, eram problematizados, subvertidos, transgredidos. Pesquisas passavam a lançar mão, cada vez com mais desembaraço, de lembranças e de histórias de vida; de fontes iconográficas, de registros pessoais, de diários, cartas e romances. (LOURO, 1997, p. 19).

Não apenas tem produzido uma crítica contundente ao modo dominante de produção do conhecimento científico, como também propõe um modo alternativo de operação e articulação nesta esfera. Além disso, se consideramos que as mulheres trazem uma experiência histórica e cultural diferenciada da masculina, ao menos até o presente, uma experiência que várias já classificaram como das margens, da construção miúda, da gestão do detalhe, que se expressa na busca de uma nova linguagem, ou na produção de um contradiscurso, é inegável que uma profunda mutação vem-se processando também na produção do conhecimento científico. (RAGO, 1998, p. 03, grifo nosso).

As mulheres escreviam e denunciavam as violências simbólicas e físicas vivenciadas, e essa forma de subjetividade deu voz e vez àquelas que antes eram subalternizadas. Suas vidas, suas sexualidades, seus gêneros, sua família e seu cotidiano eram valiosos aos olhares epistemológicos das estudiosas feministas.

Nesse embate credível proposto pela revolução feminista e pela revolução LGBT, as mulheres lésbicas e bissexuais confrontaram a heteronormatividade, assumindo uma identidade fluída, transversalisando os corpos "construindo identidades sexuais e de gênero fora dos modelos de masculinidade e feminilidade e de relações afetivo-sexuais convencionais" (GALINKIN; ISMAEL, 2011, p. 6). Nesse cenário, gênero terá um caráter social, transformando o cenário dos estudos feministas, e as discussões terão um caráter de identidade. Como bem problematiza a historiadora feminista Joan Scott (1990), as relações de gênero são:

Uma maneira de indicar "construções sociais" - a criação inteiramente social de idéias sobre os papéis adequados aos homens e às mulheres. É uma maneira de se referir às origens exclusivamente sociais das identidades subjetivas dos homens e das mulheres. O gênero é, segundo esta definição, uma categoria social imposta sobre um corpo sexuado. Com a proliferação dos estudos dos sexos e da sexualidade, o gênero tornou-se uma palavra particularmente útil, pois ele oferece um meio de distinguir a prática sexual dos papéis sexuais consignados às mulheres e aos homens. (SCOTT, 1990, p. 7).

Com as conquistas dos movimentos sociais de identidade (grupos étnicos, raciais, de classe e sexuais), os estudos feministas, juntamente com os estudos culturais, entendem "os sujeitos como tendo identidades plurais, múltiplas; identidades que se transformam, que não são fixas ou permanentes, que podem até mesmo ser contraditórias" (LOURO, 1997, p. 24). 
A IDENTIDADE LÉSBICA COMO EXPERIÊNCIA CREDÍVEL DE EXISTÊNCIA DENTRO DO COLETIVO LGBT LUTAS E CORES DE CARUARU/PE

O feminismo contemporâneo encontra suas tendências e especificidades no local onde está inserido e de onde surge sua investigação social sobre a situação da vida das mulheres. Diante desse quadro de saberes localizados ${ }^{7}$, as epistemologias feministas latino americanas se encontram dentro desses processos, como nos orienta Alonso e Díaz (2012), apontando como revisar e debater as categorias de subalternização e colonização que outrora fora colocada às mulheres:

Producir colectivamente categorias que nos ayuden a compreender y transformar el presente; esto implica introducirmos en a) debates al interior del las teorias feministas y del movimento feminista en América Latina, en torno a qiénes tienen privilégios epistémicos para anunciar problemas, caracterizar relaciones sociales, interpretar el presente y el passado, presentear alternativas al ordem social imperante; b) debates em torno a las teorias descoloniales y de los movimientos sociales, campesinos, indígenas y afrodescendientes em América Latina y las potencialidades para la investigacion social que producem "desprendimientos" de las concepciones cualitativas normativas, incluso las provenientes de las teorías críticas (ALONSO; DÍAZ, 2012, p. 77).

É dentro desse cenário atual que os feminismos irão atuar, combatendo as colonizações do corpo, da linguagem e dos saberes, desnaturalizando a concepção de um feminismo universal (branco, heterossexual e de classe média), trazendo para o debate as intersecções e especificidades do lugar global e local da mulher. $O$ feminismo latino americano será pautado nas experiências de vida das mulheres e nas suas identidades fluídas e mutáveis. Dentro desse contexto, a experiência de lésbicas feministas é pauta importante dos coletivos.

Combatendo o patriarcado ${ }^{8}$ e criando novos arranjos sociais, as práticas educativas feministas (LOURO, 1997) entram nos processos pedagógicos das escolas, dos coletivos sociais feministas e em políticas públicas com o objetivo de combater o sexismo ${ }^{9}$, criando politicamente uma educação não-sexista, pautada nos Direitos Humanos. Ancorados em Louro (1997), trazemos a seguir um quadro síntese de argumentos feministas para se trabalhar uma pedagogia libertadora de estereótipos de gênero:

Pedagogia Feminista

- Um conjunto de estratégias, procedimentos e disposições que devem romper com as relações hierárquicas presentes nas salas de aula tradicionais (p. 113)

\footnotetext{
7 Para uma análise mais profunda ver Donna Haraway, 1995.

8 La noción de patriarcado tiene partidarias y detractoras dentro del feminismo. Las primeras la suscriben en tanto permite identificar el conjunto de relaciones sociales que sustentan la dominación de los hombres sobre las mujeres a través de los pactos que ellos establecen, orientados por la interdependencia y la solidaridad (CASTAÑEDA, 2008, p. 12).

9 El sexismo que sustentan la identificación de la ciencia con el pensamiento masculino y del científico con el hombre que lo ejerce. (CASTAÑEDA, 2008, p. 42).
} 
- Pretendem estimular a fala daquelas que tradicionalmente se veem condenadas ao silêncio, por não acreditarem que seus saberes possam ter alguma importância ou sentido (p. 114)

- A situação ensino/aprendizagem se transforma numa relação onde todos os personagens podem alternar, constantemente, suas posições, sem que nenhum sujeito (ou mais especificamente, sem que a/o professor/a) detenha, a priori, uma experiência, um saber ou uma autoridade maior do que os demais (p. 114)

- Pretendem a "conscientização", a "libertação", ou a "transformação" dos sujeitos e da sociedade (p. 115)

- Pretendem interferir na dinâmica das escolas e universidades (transformando-a), elas se instalam e se exercitam nestes espaços, ou seja, elas são também, pedagogias institucionais (p. 116)

As práticas educativas feministas têm um caráter libertador e subvertem o jogo das relações de poder dentro e fora dos espaços sociais e escolares e no âmbito de políticas públicas, colaborando direta e indiretamente com muIheres feministas ou investigadores pró-feministas, como no meu caso. E toda essa trama se configura e se relaciona para uma educação não-sexista.

\section{Metodologia}

Este artigo se deu pela abordagem de pesquisa qualitativa por acreditarmos no seu caráter social dentro do universo das ciências humanas e sociais. Ao situar a abordagem qualitativa como abordagem social que não pode ser quantificada e classificada, como é comum nas ciências exatas, compreendemos que a realidade do campo social pesquisado tem seus aprofundamentos e significados. Segundo Lage (2013) e Mirian Goldenberg (2004):

A pesquisa qualitativa tem um viés que leva o investigador ao encontro de subjetividades que não conseguem se esconder, como acontece no universo da pesquisa quantitativa. As subjetividades afloram das regras e condicionamentos prévios, no contato, no diálogo e no confronto da realidade. Entender estas subjetividades e delas extrair novas compreensões requer metodologias claras, que possam admitir a diversidade de discursos, sentidos e sentimentos inéditos dos sujeitos de pesquisa em seus lugares de atuação. (LAGE, 2013, p. 50).

Aos dados da pesquisa qualitativa objetivam uma compreensão profunda de certos fenômenos sociais apoiados no pressuposto da maior relevância do aspecto subjetivo da ação social. Contrapõem-se, assim, à incapacidade da estatística de dar conta dos fenômenos complexos e da singularidade dos fenômenos que não podem ser identificados através de questionários padronizados. (GOLDENBERG, 2004, p. 49). 
Compreender as experiências, os valores, os jogos sociais, as atitudes, os confrontos e as representações fazem da abordagem qualitativa um campo de experimentações reais, uma ecologia dos saberes (SANTOS, 2003), traçando novas descobertas e do fazer do universo pesquisado um campo fértil de novas descobertas e novas (re)elaborações de conhecimentos.

Como Lage (2013) e Goldenberg (2004) nos orientam, a abordagem qualitativa prevê uma investigação científica pautada nas significações e subjetividades dos sujeitos e sua realidade social, com métodos e técnicas variados que se assemeIham também com as colaborações de Minayo (2008, p. 26-27), que bem aponta:

- A fase exploratória consiste na produção do projeto de pesquisa e de todos os procedimentos necessários para preparar a entrada no campo. É o tempo dedicado- e que merece empenho e investimento- a definir e delimitar o objeto, a desenvolve-lo teoricamente e metodologicamente;

- O trabalho de campo consiste em levar para a prática empírica a construção teórica elaborada na primeira etapa. Essa fase combina instrumentos de observação, entrevistas ou outras modalidades de comunicação e interlocução com os pesquisados, levantamento de material documental e outros;

- Análise e tratamento do material empírico e documental, diz respeito ao conjunto de procedimentos para valorizar, compreender, interpretar os dados empíricos, articulá-los com teoria que fundamentou o projeto ou com outras leituras teóricas e interpretativas cuja necessidade foi dada pelo trabalho de campo.

As abordagens qualitativas, assim como outras existentes, fazem da ciência um campo novo de experimentações, e a cada passo dado, seu rigor científico ganha mais notoriedade dentro de outros modelos já existentes.

\subsection{Fonte de informação e Técnica de Coleta}

Nossa fonte de informação neste artigo foram três jovens lésbicas que residem em caruaru-PE, as quais são integrantes do Coletivo LGBT Lutas e Cores e de outros coletivos feministas. Para preservar as identidades das companheiras, usaremos os nomes Maria Lacerda de Moura ${ }^{10}$, Nísia Floresta11 e Pagu $^{12}$ para designá-las. Outras fontes que investigamos, a partir de uma cuidadosa pesquisa bibliográfica, foram teóricos/as que fundamentam seus estudos nas áreas de gênero, sexualidade e educação tanto em periódicos quanto 10 Maria Lacerda de Moura (Manhuaçu, 16 de maio de 1887 — Rio de Janeiro, 20 de março de 1945) foi uma militante anarquista brasileira que se notabilizou por seus escritos feministas.

11 Nísia Floresta (Papari, atual Nísia Floresta, 12 de outubro de 1810 - Rouen, França, 24 de abril de 1885) foi há grande pioneira feminista brasileira, consagrando sua vida em prol da emancipação feminina no contexto sexista e patriarcal que eram submetidas as mulheres brasileiras.

12 Patrícia Rehder Galvão (São João da Boa Vista, 9 de junho de 1910 - Santos, 12 de dezembro de 1962), conhecida pelo pseudônimo de Pagu, foi uma escritora, poeta, diretora de teatro, tradutora, desenhista, jornalista e militante feminista no cenário da política brasileira. 
em livros ou documentos, numa perspectiva pós-estruturalista. Nos encontros agendados com as militantes lésbicas, para não impor de alguma maneira as participantes e não as forçar a dar respostas ensaiadas, optamos pela entrevista semiestruturada ou informal que tem o objetivo "menos estruturado possível e só se distingue da simples conversação porque tem como objetivo básico a coleta de dados" (GIL, 2008, p. 111).

\subsection{Método de pesquisa}

Na pesquisa, usamos o método do caso alargado desenvolvido pelo Sociólogo Boaventura de Sousa Santos (1983), que tem sua origem na antropologia cultural e social. Esse método consiste no estudo de um caso isolado (uma realidade), ao qual alargamos suas especificidades ao encontro de outros fatores que se uniam ou não aos casos não conhecidos. Dessa maneira, o método do caso alargado propõe que:

Em vez de reduzir os casos às variáveis que os normalizam e tornam mecanicamente semelhantes, procura analisar, com o máximo de detalhe descritivo, a complexidade do caso, com vista a captar o que há nele de diferente ou de único. A riqueza do caso não está no que nele é generalizável, mas na amplitude das incidências pela multiplicidade e profundidade das interações que os constituem (SANTOS, 1983, p. 11e 12).

Desta forma, para estudarmos as experiências de jovens lésbicas no confronto ao seximo e da lesbofobia, precisamos de um campo empírico específico, caso contrário não seria possível dar conta de todas os confrontos que elas travam todos os dias. A partir do estudo desse caso, é possível, através do método do caso alargado, estender a outros campos, contemplando, assim, a urgência da identidade lésbica como lugar de resistência aos modelos e as políticas de gênero interpelados nos corpos e nos desejos das jovens lésbicas, segundo Lage (2013):

Sendo assim, o Método do caso alargado propicia uma conclusão de maior profundidade sobre a investigação realizada, incidindo não apenas sobre os casos estudados- isoladamente ou comparados- mas porque oferece uma estrutura metodológica capaz de ampliar o espectro das reflexões, amplia o universo de questões importantes relacionadas com o tema e presentes na sociedade. (LAGE, 2013, p. 56).

\section{Resultados e discussão}

Nosso caminho teórico-metodológico buscou o método do caso alargado (SANTOS, 1983) para a análise das experiências de jovens lésbicas no 
enfrentamento do sexismo e da lesbofobia. Para Santos (1983): "A riqueza do caso não está no que há nele de generalizável, mas na amplitude das incidências estruturadas que nele se denunciam pela multiplicidade e profundidade das interacções que os constituem" (SANTOS, 1983, p. 12).

Tomando nosso problema "quais as experiências das mulheres lésbicas do Coletivo LGBT Lutas e Cores no enfrentamento da lesbofobia e do sexismo?", decidimos sistematizar a pesquisa em duas categorias que apontam as interpretações e os aspectos discursivos para o amplo desenvolvimento de uma intencionalidade pedagógica pautada na valorização das identidades lésbicas, dentro de uma perspectiva não-sexista e no enfrentamento à lesbofobia. Foram elas:

\subsection{Lesbianeidade: entre identidades e resistências}

A identidade lésbica surge como resistência a partir do momento em que as jovens lésbicas saem do armário e pautam em suas redes de sociabilidade sua identidade. Nesse momento, a carga de preconceito sobre essas mulheres recebe uma dupla forma de violência e discriminação. Por se tratar de uma identidade feminina, a lésbica já nasce em uma sociedade androcêntrica, patriarcal, machista e misógina, sendo assim, já está inserida dentro de uma lógica binária de classificação social como nos aponta Santos (2003), Olga Viñuales (2002) e Castañeda (2008). Na outra face da violência, está a identidade lésbica como identidade silenciada, negativa, desenhada como não existente e, portanto, fabricada como não-credível de existência.

A experiência de revelar sua identidade afetiva e sexual (orientação sexual) para a família, os grupos de amigos e em outros espaços, como o trabalho, são processos pelos quais toda a pessoa LGBT passa em sua jornada de vida. Com as lésbicas, a saída do armário ocorre sobretudo nos espaços de amizade com grupos que possuem a mesma intencionalidade política de identidade ou em espaços da Universidade/Faculdade. Como nos contam nossas militantes lésbicas:

Num determinado estágio da minha vida eu me vi mais esclarecida com mais conhecimento, mais independência, mais autonomia de vontades e desejos, a partir do momento que eu começo a conhecer as pautas de inclusão social e igualdade, o feminismo pra mim é um grande estandarte de revolução pra mim, por que me fez enxergar o mundo de uma maneira mais autônoma e independente de fato sem a égide da religião ou de qualquer coisa que seja me fez abrir a mente sobre ter o direito de escolha sobre o meu corpo, meus desejos minha vida. Só ano passado em 2016 passei a entender que de fato orientação sexual vem muito do desprazer do desejo e tudo mais e não meramente de um beijo na boca. Passei a entender de outras formas e me identificar e romper o estigma social dentro de mim e me aceitar como mulher como lésbica e socialmente como sapatão. (MILITANTE LÉSBICA NÍSIA, 2017). 
Talvez eu não encarasse como uma doença. Foi muito difícil me reconhecer enquanto mulher lésbica. Eu digo que sou um pouco privilegiada porque eu não tenho uma família que é homofóbica ao extremo a ponto de dizer: eu não quero filha minha lésbica! Tem as questões que também são gerações diferentes. Eu acreditava mais na questão de escolha. Eu pensava que era uma escolha sexual, que você escolhia ser lésbica ou ser gay, enfim. Nunca tive contato da pessoa trans, da pessoa travesti. Nisso eu englobava tudo numa coisa só. Daí eu tentava escolher ser hétero. Eu só conseguir mesmo quando eu já tava na faculdade daí eu cursava uma disciplina de psicologia social, eu fui me desconstruindo nessa disciplina. Eu fiz terapia e reconheci que aquilo não era um problema. Eu não encarava como uma doença, mas como um problema. Algo que eu poderia escolher ou não. (MILITANTE LÉSBICA MARIA LACERDA DE MOURA, 2017). Pra mim também foi muito doloroso. Na base familiar eu ouvia que era doença, que tinha que procurar ajuda. Que tinha que procurar um padre pra conversão. Que tinha que procurar terapia porque estava doente. Eu não me sentia doente, mas eu não entendia. Vindo de uma família do interior, você não conhece os LGBTs na cidade, daí também não quer ser a fofoca na boca dos outros. Passei metade da minha adolescência ouvindo que era doença. Não ouvi diretamente comigo mas aparecia um casal lésbico na novela e na escola começavam a falar que era doença. E eu comecei a mim questionar: será que eu sou doente?. E também tinha medo de me consultar com um profissional por que ele poderia contar pra minha família. Foi também na faculdade que eu comecei a mim conhecer melhor, é um espaço onde você está fora de casa, está passando da adolescência para a juventude. Vai descobrindo uma liberdade e uma individualidade muito grande. Você encontra gente de todo o jeito. Tem que estar se afirmando politicamente. Primeiro eu me percebi enquanto mulher lésbica, depois enquanto mulher lésbica negra. (MILITANTE LÉSBICA PAGU, 2017).

Como podermos perceber, a saída do armário para as meninas lésbicas foi um momento de grande resistência e também de grande sofrimento. Não é fácil respirar uma única possibilidade de existência, a norma heterossexual, e confronta-la de maneira eficiente com núcleos familiares ou redes de amizade próximas. Surgem dúvidas, preocupações, dores e medo. O sentimento é de grande passagem, e, uma vez livre das amarras da lesbofobia e do sexismo, a resistência precisa ser semeada e cultivada todos os dias. Olga Viñuales (2002) nos relata como o processo de saída do armário possibilita também uma outra reconfiguração na vida das meninas lésbicas:

El processo de toma de conciencia de la diferencia modifica la manera en que una persona se valora a sí misma y a los demás. Es una etapa de la vida que suele dilartase en el tiempo y en la que se observan una serie de conductas que, por su recurrencia, podemos deducir comunes a otras lesbianas: la necesidad de explicar a otras personas cuanto les está sucediendo y la inquietud ante la reación de los otros, especialmente de los seres más queridos (VIÑUALES, 2002, p 77). 
Como bem problematiza Viñuales (2002), a fronteira simbólica da lesbianeidade será uma possibilidade credível para as lésbicas se encontrarem e buscarem, nas histórias de vida de outras meninas, as suas experiências e a troca de afetividades. Temos acompanhado em muitas séries de TV ${ }^{13}$, filmes ${ }^{14}$ e novelas ${ }^{15}$ o tema da lesbianeidade como proposta credível para enfrentar o preconceito lesbofóbico e quebrar os paradigmas fundamentalistas que acusam a identidade lésbica de anormalidade e perversão sexual.

Outras fontes de interação são os aplicativos ${ }^{16}$ de celular que já trabalham com perfis de relacionamento diversos, em que se criam redes de apoio e afetividade entre as lésbicas. Como bem questiona Míriam Martinho (2013), fundadora do Movimento Lésbico Brasileiro sobre a visibilidade lésbica na contemporaneidade:

E não há dúvidas de que a visibilidade lésbica está na ordem do dia, presente na pauta da mídia escrita e televisiva e nas manifestações de rua. Estratégia de combate ao preconceito, ela prega que muitos dos mitos existentes sobre as mulheres que amam mulheres advém de fato de que a sociedade não as conhece porque elas permanecem escondidas, "invisíveis", temerosas dos efeitos da discriminação em suas vidas. Esconder-se, porém, de acordo com a teoria da visibilidade, embora natural reação de defesa diante do preconceito e inclusive estratégia de sobrevivência em algumas situações, é uma faca de dois gumes: se de um lado protege, do outro alimenta as ideias preconcebidas da população obre as mulheres homossexuais e as mantém reféns de culpas e vergonhas sem sentido. (MARTINHO, 2013, p. 06).

Portanto, a identidade lésbica quebra com os paradigmas essencialistas (macho/fêmea) e dicotômicos (mulher/lésbica) imposto pela sociedade heteronormativa, fazendo de sua performatividade de gênero uma experiência concreta e digna de existência como qualquer outra, criando, dessa forma, espaços de sinceridade, familiaridade, igualdade e luta política.

\subsection{Enfrentamento da Lesbofobia e do Sexismo}

É no enfrentamento da lesbofobia e do sexismo que as militantes lésbicas do Coletivo LGBT Lutas e Cores encontram suas forças e seus espaços de voz e vez para atuarem como protagonistas. As estratégias de enfrentamento e a busca da promoção e valorização das identidades lésbicas são fabricadas como respostas práticas ao preconceito naturalizado e aceito livremente pela sociedade.

13 Produzida desde 2013, a série The Fosters narra a história de duas mulheres lésbicas (uma negra e uma branca) e seus dilemas para criar seus quatro filhos adotivos junto com um filho biológico.

14 Lançado em 14 de janeiro de 2016 pela Mares Filmes, o Filme Carol conta a arrebatadora história de duas mulheres que se aproximam depois de viverem experiências comuns ao seu gênero: filhos e divórcio. Com o passar do tempo surge uma afetividade entre ambas e os desdobramentos dessa nova vida.

15 No ano de 2014 a novela escrita por Manoel Carlos "Em Família" abordou o tema da lesbianeidade entre as personagens Clara (Giovanna Antonelli) e Marina (Tainá Müller). Podemos vivenciar até mesmo um beijo entre as personagens, tema ainda tabu nos lares brasileiros.

16 site OBA OBA traz até sete opções de aplicativos de paquera para o público de lésbicas. Link para acesso: https://www.obaoba.com.br/pegacao/noticia/7-aplicativos-lesbicos-para-conhecer-garotas. 
Como forma de combate, as estratégias utilizadas pelo Coletivo LGBT Lutas e Cores são formações pedagógicas em escolas, locais institucionais como prefeituras e espaços acadêmicos como Universidades e Faculdades. Todos esses espaços demandam das militantes lésbicas que suas experiências sejam credíveis e que sua intencionalidade educativa seja credível também como suporte epistemológico.

Eis alguns exemplos de como o Coletivo LGBT Lutas e Cores, por meio de suas militantes lésbicas, trabalham com as temáticas de valorização das identidades lésbicas:

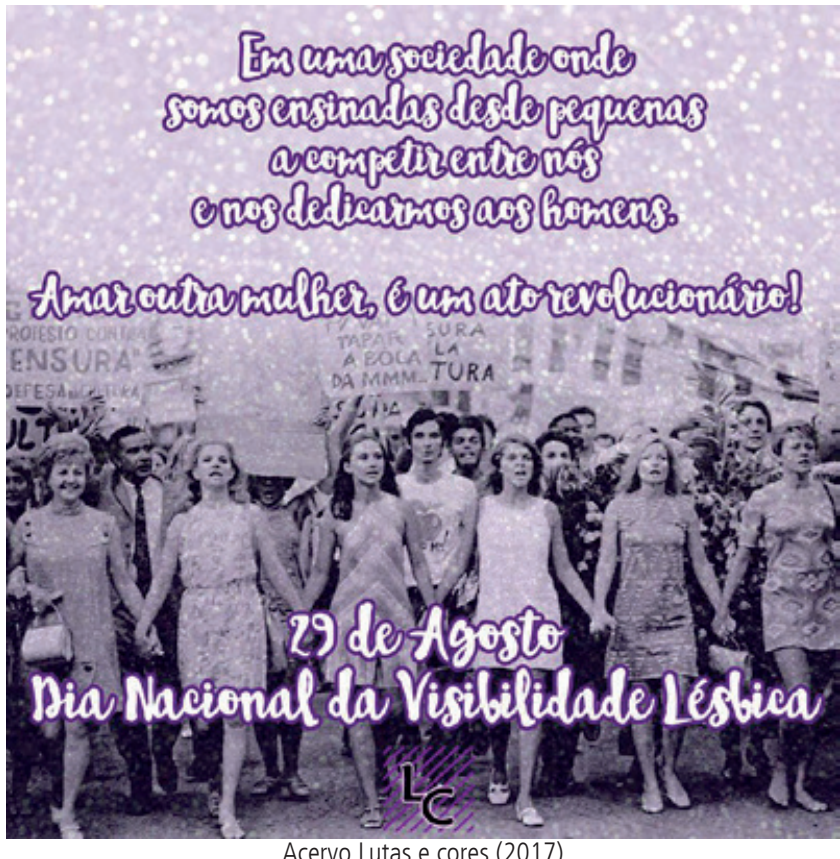

Acervo Lutas e cores (2017)

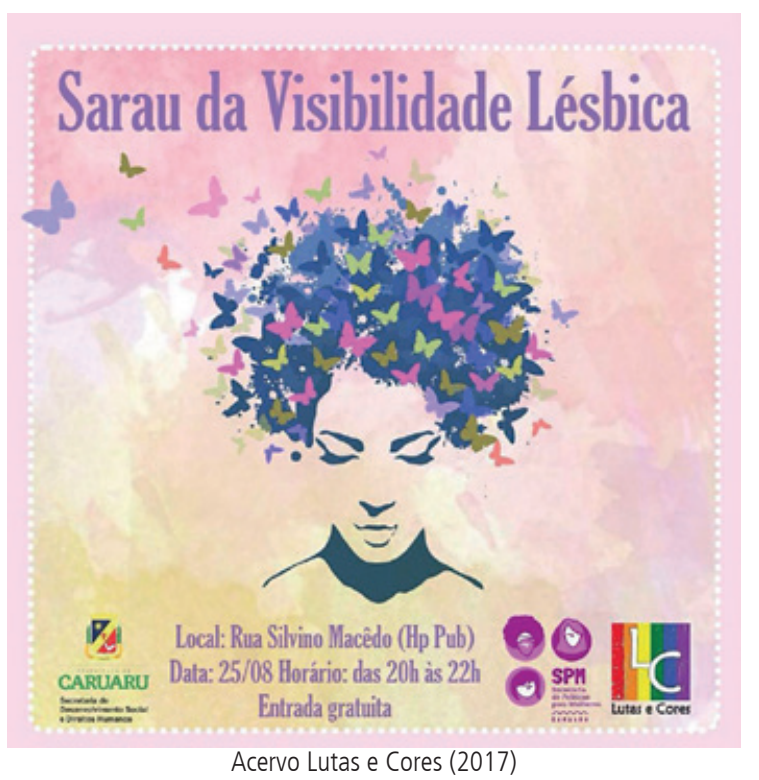


A IDENTIDADE LÉSBICA COMO EXPERIÊNCIA CREDÍVEL DE EXISTÊNCIA DENTRO DO COLETIVO LGBT LUTAS E CORES DE CARUARU/PE

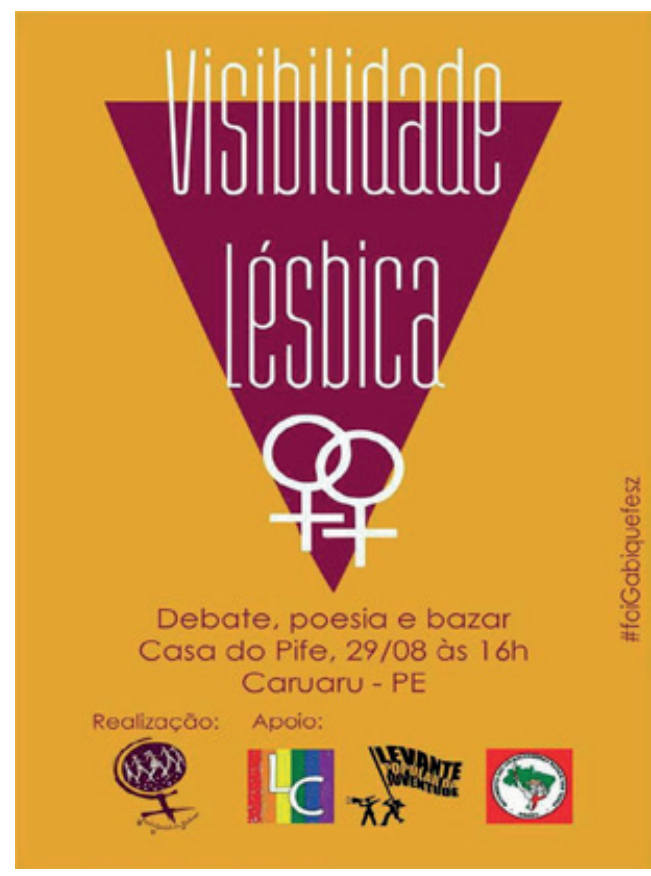

Acervo Lutas e Cores (2017)

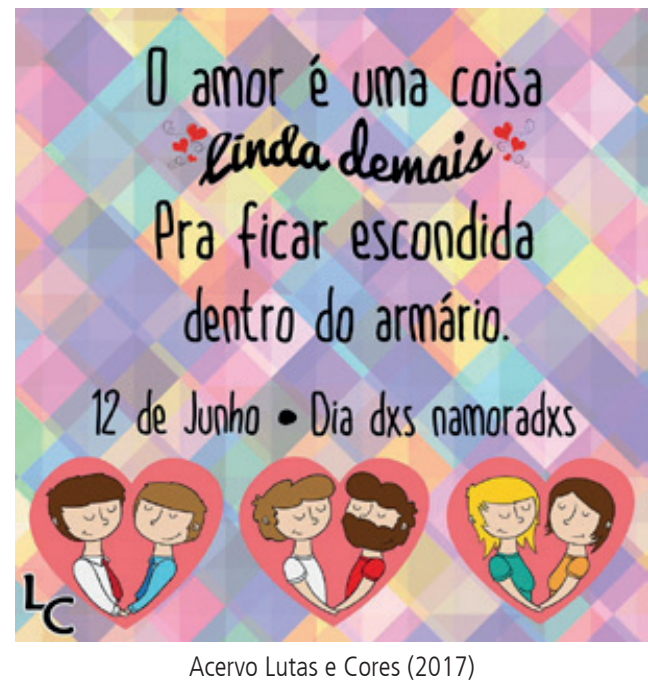

\section{Considerações finais}

É na formulação, elaboração, participação e implementação dessas atividades acima que as militantes lésbicas desconstroem ideários lesbofóbicos e sexistas no cenário caruaruense. Suas experiências como fenômeno de uma existência ética trazem para a vida dessas militantes a liberdade como suporte de uma vida digna, como bem nos falam nossas militantes sobre a importância de estarem inseridas em um coletivo LGBT de visão horizontal e preocupado em pautar todas as identidades LGBTs como credíveis de existência. 


\section{Referências bibliográficas}

ALONSO, Graciela; DÍAZ, Raúl. Reflexiones acerca de los aportes de las epistemologias feministas y descoloniales para pensar la investigacíon social. Dossie: Pensamiento crítico y cambio. Ano 1, n 1, 2012.

ÁVILA, Maria Betânia, GOUVEIA, Taciana. Lesbianidade e Cidadania. Bocas no Mundo Ano I n² 2, Revista da Articulação de Mulheres Brasileiras - AMB, julho de 2003

BORRILO, Daniel. Homofobia: história e crítica de um preconceito. Belo Horizonte: Autêntica, 2010

CASTAÑEDA, Martha Patricia Salgado. Metodología de la investigación feminista. Fundación Guatemala Centro de Investigaciones Interdisciplinarias en Ciencias y Humanidades Universidad Nacional Autónoma de México. Antigua Guatemala, Colección diversidad feminista, abril de 2008.

GALINKIN, A.L; ISMAEL, E. Gênero. Camino L.; Torres A. R.; M.E.; Pereira, M.E. (Org.). Psicologia Social: Temas e teorias. $1^{\circ}$. ed. Brasília: Technopolik Ed., 2001

GIL, Antônio Carlos. Como elaborar projetos de pesquisa. 4 ed. São Paulo: Atlas, 2002

GOLDENBERG, Mirian. A arte de pesquisar: Como fazer uma pesquisa qualitativa em ciências sociais. Rio de Janeiro: Record, 2004

LAGE, Allene. Educação e Movimentos sociais: caminhos para uma pedagogia de luta. Recife: ed. Universitária da UFPE, 2013.

LOURO, G. L. Gênero, sexualidade e educação: uma perspectiva pós-estruturalista. Petrópolis, RJ: Vozes, 1997

MARTINHO, Mírian. Visibilidade Lésbica: o que os olhos vêem, o coração sente!!. Bocas no Mundo Ano I $n^{\circ}$ 2, Revista da Articulação de Mulheres Brasileiras - AMB, julho de 2003.

MINAYO, M. C. S. (Org.); DESLANDES, S. F.; CRUZ NETO, O. GOMES, R. Pesquisa social: teoria, método e criatividade. 27. ed. Petrópolis, RJ: Vozes, 2008.

PEREIRA, Cleyton Feitosa, SANTOS, Emerson Silva. Estratégias educativas do movimento LGBT de caruaru: um relato de experiência das ações do coletivo lutas e cores. In: Anais do II Seminário Internacional do Observatório dos Movimentos Sociais na América Latina. Universidade Federal de Pernambuco - Centro Acadêmico do Agreste UFPE/CAA, 2016. Link para acesso: http:// observatorioufpecaa.blogspot.com.br/2016/11/anais-do-ii-seminario-internacional-do.html acessado em: 15/11/2017.

PRADO, Marco Aurélio Máximo; MACHADO, Frederico Viana. Preconceito contra homossexualidades: A hierarquia da invisibilidade. São Paulo: Cortez, 2008.

RAGO, Margareth. Epistemologia Feminista, Gênero e História. Disponível em http://projcnpq. mpbnet.com.br/textos/epistemologia_feminista.pdf. Acesso em 08/12/2017

RICH, Adrienne. Heterossexualidade compulsória e existência lésbica. Revista Bagoas, n. 5, 2010, p. 17-44.

SANTOS, Boaventura de Sousa. Os conflitos urbanos no Recife: o caso do "Skylab". Revista crítica de Ciências Sociais, n 11, maio, pág. 9-59. Coimbra: Centro de Estudos Sociais, 1983. Para uma Sociologia das ausências e das Emergências. Porto: Edições Afrontamento, 2003.

SCOTT, Joan. Gênero: uma categoria útil de análise histórica. In: Educação \& Realidade. V. 16, n 2 , jul./dez. Porto Alegre: UFRGS, 1990.

SIMÕES, Júlio Assis; FACCHINI, Regina. Na Trilha do Arco-Íris: Do movimento homossexual ao LGBT. São Paulo: Fundação Perseu Abramo, 2009

SMIGAY, Karin Ellen von. Sexismo, homofobia e outras expressões correlatas de violência: desafios para a psicologia política. In: Psicologia em Revista, Belo Horizonte, v. 8, n. 11, p. 32-46, jun. 2002

VIÑUALES, Olga. Lesbofobia. La Biblioteca del Ciudadano. Edicions Bellaterra, 2002. 